\title{
A má política em cena
}

\author{
Maria de Fátima Silva \\ Universidade de Coimbra \\ fanp@ci.uc.pt
}

RÉSUMÉ: Les Chevaliers d'Aristophane ont représenté, dans la carrière de son auteur, un moment particulier. Quand Aristophane présentait, pour la première fois, une pièce sous son propre nom il obtenait aussi un premier prix. Ce que le poète faisait, à ce moment, privilégiait la satire politique, suivant l'exemple d'un prédecesseur distingué, Cratinus. L'humour et la vibration des Chevaliers rivalisaient avec la vigueur de son modèle de l'ancienne génération.

MOTS-CLÉS: Comédie Grecque ; caricature politique; Cléon; mise-en-scène.

A opção de Aristófanes, em 424 a. C. - trazer à cena, pela primeira vez em seu próprio nome, um ataque aos demagogos - tinha subjacente um impacto inegável. A ousadia prometia sucesso, como veio a ser confirmado pelo primeiro prêmio obtido. Vários foram os impulsos que levaram a esta preferência. De natureza política, em primeiro lugar. Morto Péricles em 429, a governação da Atenas democrática prosseguiu no sentido de uma crescente radicalização. Após um período de alguma indefinição, Cléon surgia, dois anos passados sobre a morte do Alcmeônida (427), como paradigma de um outro modelo de figura pública: o demagogo, que em breve se tornou uma espécie de tipo social e teatral. A experiência de meia dúzia de anos de demagogia permitia já um balanço, feito em termos simbólicos; não se tratava apenas de caricaturar

um modelo da classe, o famoso Cléon, que parecia ter, em pouco tempo, levado a "demagogice" a um clímax de sucesso. Aristófanes vai mais longe; parte do modelar Cléon para "o padrão ideal" do demagogo, encarnado num Salsicheiro, esse sim a imagem perfeita e acabada da personagem. Em vez da receita perscrita por outros poetas da comédia - caso de Êupolis, frs. 90-131 de Demos, "procuremos regressar aos velhos tempos e recuperar um ou dois homens com letra grande" -, o poeta de Cavaleiros propunha: "para te livrar de um demagogo, só outro pior do que ele".

Ao tom direto que a denúncia da demagogia revestia em relação a acontecimentos do momento, Aristófanes somava motivos pessoais. Insistir no ataque a Cléon era também, na sua ainda curta carreira de homem de teatro, um teste arriscado, quando as relações poeta/ demagogo andavam azedas. Depois que, desagradado com as críticas de que tinha sido objecto em Babilónios (426 a. C.), Cléon tinha apresentado ao Conselho uma queixa contra Aristófanes, as relações entre os dois ficaram tensas. Que 


\section{nuntius antiquus}

tratamento teria, entretanto, dado o Conselho ao protesto do poderoso político? Não se sabe, mas a própria ousadia de Cavaleiros mostra a tolerância da autoridade pública e alguma segurança que comunicou a um poeta atrevido. O conflito ainda morno contribuía, assim, para dar à peça de 424, além de um sentido de atualidade, o sabor de um desafio.

Por fim, uma razão de nível artístico e profissional pode também ser invocada. Estes eram os anos em que Cratino, o grande rival de uma geração que agora chegava ao fim, tinha marcado a comédia com um impacto tremendo através da crítica pessoal desassombrada. Na parábase de Cavaleiros (526-536), o coro recorda-lhe o rigor inédito e a popularidade que conquistou. Voltar contra Cléon, e os seus parceiros na gestão da cidade, uma receita que tão bem funcionara no ataque contra Péricles, levado a cabo por Cratino, parecia uma tentativa promissora de aproveitar uma onda de sucesso. Numa palavra, diversos fatores confluíam para fazer de Cavaleiros o primeiro grande êxito da carreira de Aristófanes.

Se a escolha do assunto obedeceu a um sentido de oportunidade, a execução do projeto revelou um talento de que o jovem poeta vinha já dando mostras. Dos vários méritos da peça - o vigor que resulta da concentração e intensidade do motivo escolhido e da estrutura usada, e a qualidade poética -, vamos sobretudo focar-nos na imaginação criativa, que faz de um quadro "realista" uma fantasia sugestiva. Acontecimentos, personagens, contexto político são os do imediato citadino. Mas sobre eles Aristófanes constrói, com um distanciamento verdadeiramente universal, um jogo de símbolos. Melhor do que "o retrato de Atenas em 424", o quadro produzido merece, por legenda, "os vícios atemporais da demagogia".

A metamorfose do concreto no paradigmático processa-se a vários níveis. Vejamos, antes de mais, as personagens. O alvo central da peça é, como vimos, Cléon. A sua caracterização reúne, a par de uns poucos traços individuais, um conjunto de características que o convertem num tipo. Desde logo o nome. Em vez de Cléon, o Paflagônio. E não se trata de ocultar ou de acautelar em ambiguidades uma possível reação do visado, porque tudo na peça contribui para o retrato inequívoco do político. Trata-se sim de lhe dar um cognome a caráter com a marca da sua atuação pública. Paflagônio é, numa primeira impressão, nome de escravo, artigo de importação vindo de longe, do norte da Ásia Menor, uma compra de última hora e, como todos os da sua classe, "uma peste" (v. 2). Sem um nome de família que o integrasse, com legitimidade, 


\section{nuntius antiquus}

entre os cidadãos - ele que se assumiu como condutor dos seus destinos -, o Paflagônio soube, no entanto, conquistar um lugar ao sol no mundo dos negócios. É essa conjugação feliz que permite associar, ao seu nome de origem, o de uma profissão de sucesso que passou a ser a sua imagem de marca: o Paflagônio dos curtumes, byrsopaphlagôn (v. 47). Mais ainda: paphlagôn não é só a sugestão de uma origem remota; tem uma sonoridade aparatosa, onomatopaica, como de bolhas que rebentam, para aludir ao estrondo da sua voz e dos seus argumentos, a mais eficaz das suas ferramentas. Com o nome apenas, Aristófanes lançava os alicerces de um outro tipo de figura pública, bem distante dos homens de Estado tradicionais, aristocratas, educados, polidos, de raiz ateniense, de que Péricles tinha sido o exemplo acabado. $\mathrm{O}$ retrato construído com epítetos é por si só nítido, de modo que se lhe pode dispensar a máscara. Da figura que o público vê em cena, tem de se reconhecer (v. 230-233): "Não tenhas medo, que o tipo não está nada parecido. É tal o cagaço, que não houve um único fabricante que lhe quisesse fazer a máscara. Mesmo assim vai ser reconhecido. $O$ público é de olhão!"’. O medo é provavelmente a expressão da cautela de um poeta que não quer agudizar a querela que vem mantendo com o demagogo.

Cléon apareceu na linha do que se poderia chamar "uma dinastia" de demagogos, na Atenas democrática um novo modelo de "tiranos" do povo. Em hierarquia crescente, os epítetos estabelecem entre eles uma "linhagem", a dos pôlai, “os comerciantes": Êucrates, "o vendedor de estopas" (skyppeiopôles, v. 129), Lísicles, "o vendedor de gado" (probatopôles, v. 132), até Cléon, "o vendedor de coiros" (byrsopôles, v. 143). Por milagre da imaginação do poeta, a curva cómica está prestes a atingir o seu auge com o modelo pleno, o Salsicheiro (allantopôles, v. 143), a quinta essência da sucessão.

Com este achado, um Salsicheiro, Aristófanes identifica um adversário à altura de Cléon, o único que, por possuir em superlativo todas as prendas da classe, o pode destronar. Anônimo na sua qualidade de "paradigma ideal", o Salsicheiro tem também uma identidade dramática expressiva. A simples designação valoriza-lhe a modéstia, a associação com um comércio rasteiro, os traços que são próprios do mundo de oportunismos de que a Ágora é o órgão vital. Mas tal como o adversário, o nome que usa faz dele um símbolo, daquele que teve a habilidade de transformar a política na "arte de empanturrar o povo". A sua insígnia, profissional e cênica, é a banca dos chouriços (v. 152). Num rasgo de gênio, o Salsicheiro é convidado, pelos dois escravos 


\section{nuntius antiquus}

que o saúdam como a um salvador, a trepar à banca, para abranger lá de cima o seu império. É portanto do cimo do seu sucesso comercial que irá reinar (v. 169-178), numa Atenas que se tornou centro de uma rede de empórios, de portos, de ilhas, onde se agitam negócios e dinheiro.

Porque surge em cena como predestinado para uma carreira, o Salsicheiro é a massa sobre que se moldam "os políticos de hoje em dia". Ignorância, velhacaria, aldrabice, são materiais essenciais à sua construção. Se reunidos, produzem o moderno homem de sucesso. O momento da metamorfose é marcado em cena por um gesto, à primeira vista inocente. Ao dirigir-se ao Conselho para fazer uma primeira intervenção nas instâncias públicas - o seu batismo institucional -, o Salsicheiro pousa no chão facas e enchidos (v. 488-489); é o gesto simbólico de quem abandona um negócio, para se iniciar noutro, a política. Este gesto vai ter, no final do agon, depois de decidida a vitória do novo demagogo, a sua réplica. Apeado por sua vez do poder, o Paflagônio será condenado a pegar na mesma banca dos chouriços, para abandonar a política e regressar aos negócios (v. 1398-1399). Por consequência do jogo dramático, política e negócios desenham-se numa equação simétrica: dos negócios em ascensão até à política; da política em retrocesso até aos negócios.

$\mathrm{Na}$ dicotomia que os dois demagogos estabelecem introduz-se uma figura incontornável, Demos, o Povo. Se o olharmos como personagem teatral, o que nele reconhecemos, antes de mais, é o despotes, o patrão, como sempre em contraponto com o escravo. Desta vez, porém, o servo habitual na cena que a tradição cômica fazia remontar às suas origens (cf. $N u$. v. 541-542, "nem o velho, a dizer os versos que lhe cabem, desanca à bengalada quem lhe está por perto, para o fazer engolir piadas de mau gosto") multiplica-se numa hierarquia; no topo está o Paflagônio, desde a sua compra como intendente do senhor; em contraste com "um par de escravos", também eles um motivo cômico muito antigo (responsáveis pelas cenas de abertura de Cavaleiros, Vespas e Paz), muito provavelmente a sugerir os generais Demóstenes e Nícias. Como qualquer tradicional despotes da comédia, Demos é um velho surdo, pacóvio, azedo e agressivo (v. 40-43). Neste caso, pela força do seu simbolismo, o retrato convém não só à figura de comédia, mas também ao que se poderia chamar 'a psicologia de massas'. Em conformidade com a sua physis coletiva, a casa de que é senhor ganha o sentido simbólico da polis, o oikos dêmou. Como se estabeleceu, neste domicílio coletivo, essa escala de autoridades? Por força de pancadas, a própria concorrência pela simpatia do 
senhor (v. 5), que decide dos seus preferidos: quem mais golpes distribuir aos adversários, melhor se instala. Mas nem só em volta do patrão se estabelece uma hierarquia; ele mesmo, o próprio Demos, se movimenta no espaço cênico de forma a ir alargando o seu raio de ação: do que é simplesmente "a sua casa", a cidade em geral, para os que são, em ritmo crescente, os canais do poder, primeiro o Conselho, e depois, como expressão plena da autoridade popular em democracia, a assembleia na Pnix.

Nesta gestão doméstica precária, acontecimentos recentes vieram introduzir alterações. Eis que o par de escravos pode acrescentar às pancadas, de que sempre foi vítima, um agravo novo: verem-se afastados, que nem moscas incômodas, das proximidades do senhor; e privados daquele "pãozinho" da Lacônia que tinham cozido para o patrão - a ocupação de Pilos, em território lacedemônio, um trunfo importante para o decurso da guerra -, a que o Paflagônio deitou a unha para o oferecer ao povo como obra sua (v. 54-57, v. 778). Haveria, na caracterização dos dois escravos, alguns traços que os identificassem com as figuras dos dois generais? Se o texto não dá disso sinal seguro, pelo menos o contexto é claro. Foram Demóstenes e Nícias quem, em Pilos, cozeu o ‘pãozinho' para o Povo. É, por isso, compreensível que a peça se inicie com a procura de uma estratégia que livre a casa do Povo de tão indesejável mordomo.

O coro é constituído por cavaleiros, o que nos leva a perguntar o porquê desta preferência. É evidente que um motivo de caráter geral se ia tornando cada vez mais óbvio: a oposição social que a autoridade crescente dos demagogos exercia sobre a predominância tradicional das grandes famílias aristocráticas, numa Atenas democrática. Em 424, os cavaleiros vinham contrapor ao sucesso obtido pelo demagogo em Pilos o êxito por eles mesmos também conseguido em Corinto (Thuc. 3. 42-45). De resto, o ódio que move os cavaleiros contra Cléon harmoniza-se com o sentimento do próprio Aristófanes, também ele vítima da perseguição do demagogo após as críticas que lhe tinha dirigido numa comédia, para nós perdida, que se intitulou Babilónios. É o reconhecimento público o que reclamam para as suas montadas e indiretamente para si mesmos, para a excelência de que deram mostras (v. 595-610). Habituados a combater em terra, adequaram-se, com empenho máximo, às condições marítimas da empresa. Munidos de magras rações de combate, agiram com toda a determinação, capazes de colher de condições adversas o máximo resultado. Associada a esta fusão mimética entre cavaleiro e cavalo está a caracterização do coro em cena; a cerâmica (através do famoso vaso de figuras negras de meados do séc. VI, que representa a dupla de homens 
com cabeça e cauda de cavalos) dá testemunho da materialização visual destes versos de autoelogio.

Mas Cavaleiros salienta também o desfasamento entre a classe e a realidade citadina, dando a imagem de jovens das melhores famílias, orgulhosos da sua pujança física e da elegância das suas montadas, mas de certa forma desligados dos reveses políticos que afetam Atenas (v. 556-558); Nuvens, no ano seguinte, afina-lhes o retrato; em vez de combater, os jovens cavaleiros passaram sobretudo a vibrar com o entusiasmo das competições desportivas (v. 25, v. 29), tomados por uma espécie de fanatismo que se apoderou de uma geração de inúteis. Por outro lado, o mesmo desprestígio acarreta desvantagens econômicas, para um grupo que continua a entender o seu dever para com a pátria compensado com um simples salário; em contrapartida, os demagogos recebem benesses excepcionais e recusam-se a combater (v. 575-577). ${ }^{1} \mathrm{E}$ nesta dicotomia - patriotismo esforçado e desinteressado o de uns, ao lado da ambição individualista de outros - que reside uma divergência que, na comédia como na vida real, tende a ser diametralmente oposta.

Eis o motivo por que, na peça de Aristófanes, os cavaleiros, em nome do "ódio" a Cléon (v. 226, v. 400), se dispõem, por estranho paradoxo cômico, a apoiar na sua luta não um dos seus, um aristocrata que lhes defenda os interesses; bem pelo contrário, para seu campeão escolhem um Salsicheiro, o único detentor de um potencial de "demagogice" capaz de fazer frente ao famoso Cléon. Nesta opção, evidencia-se a capacidade que a velha classe tem ainda de entrar no jogo político, não para se impor como um grupo autônomo, mas para, com o seu voto, condicionar a competição entre os atuais decisores, os demagogos. É essa atitude de resistência que faz deles, ao lado do Povo, um trunfo ainda de peso num modelo social que se pauta por outros valores.

A procura de uma solução política - traduzindo a ideia de arredar concorrentes para ganhar a simpatia e o voto do povo - exige criatividade, ousadia, imaginação. Como se de uma arte se tratasse, necessita de uma fonte inspiradora. E como afinal, na ficção cômica, é no terreno de Dioniso que nos encontramos, a solução está no vinho. No ano seguinte a Cavaleiros, numa célebre comédia que intitulou A garrafa, Cratino defendia o poder inspirador da Bebedeira, na pessoa de um poeta com uma relação

\footnotetext{
${ }^{1}$ Esta observação visa em particular às campanhas de Pilos e Corinto. Enquanto Cléon, herói em Pilos, foi agraciado pela cidade com as refeições a expensas públicas no Pritaneu (v. 281) e com um lugar de honra nas festividades do Estado (v. 575, v. 702-704), aos cavaleiros nada mais coube do que o sentimento compensador do dever cumprido. 


\section{nuntius antiquus}

desgastada com a esposa de há muitos anos, a Comédia. E interrogava-se: "Como pode quem bebe água produzir obra de gênio?” (fr. 199K). À política, os dois escravos de Cavaleiros propunham-se aplicar receita semelhante. Talvez o velho Cratino - que era visado, na peça de 424, por Aristófanes com um gracejo pelo seu entusiasmo pelo vinho - tivesse até tomado como mote a filosofia dos escravos do Povo (v. 85-86): "Ora, ora! Temos mas é de entornar uma pinga do genuíno à nossa boa estrela. Talvez assim tenhamos uma ideia que se aproveite”. A inspiração, a primeira arma virtual da política, vem à cena sob forma de um brinde; é dele que saem as ferramentas do dia-a-dia da política, "planozinhos, frasezinhas, ideiazinhas" (v. 100). Na cena de Dioniso, o vinho é trazido para exibir as suas qualidades criativas; só depois de uma boa golada o Primeiro Escravo, de certa forma como o próprio poeta, vai passar dos lamentos, das hesitações sobre o modo de actuar, para um plano de ação (v. 105 ss.).

Com os primeiros goles de vinho começa a formar-se nos dois "conspiradores" uma consciência política. Estimulante, o vapor dionisíaco fá-los perceber que uma carreira pública é, antes de mais nada, um debate com os adversários que ocupam o mesmo terreno. Trata-se de um jogo de exclusão e exige que quem se inicia avalie primeiro o espaço em que se ensaia. Esse é, digamos, o "segredo" da política. O diagnóstico da situação, porque é determinante para o êxito ou fracasso futuro, exige o aval da divindade e será revelado por oráculos, aqueles que o Paflagônio esconde cuidadosamente, como quem protege a própria sobrevivência... política. São eles que, com sabedoria, depois de determinarem os intervenientes mais destacados da demagogia ateniense, pressagiam a revolução, essa apenas viável na comédia: a vinda salvadora do Salsicheiro.

Simbolicamente uma carreira política de sucesso faz-se de dois processos essenciais: as pancadas e agressões, que são a imagem palpável da perseguição dos adversários, e a capacidade retórica, essa expressa em diversas tonalidades. Pancadas e agressões são usadas com abundância em Cavaleiros. Sendo um processo banal na tradição cômica, podem ganhar, num contexto de paródia política, um sentido específico e sugerir a rivalidade, entre classes sociais ou entre figuras do Estado. O párodo, por convenção um momento de agressividade que marca a entrada do coro, é a primeira cena de pancadaria na peça. Mas é também a materialização de um confronto político: entre a velha aristocracia, representada pelos jovens cavaleiros, filhos das melhores famílias, herdeiros da nobreza tradicional em decadência, e os modernos demagogos. 


\section{nuntius antiquus}

Apesar de revigorados pelo êxito recente de Corinto, a verdade é que o lugar e prerrogativas da nobreza não estão seguros no universo democrático; defendê-los é cair em cima do Paflagônio (v. 247-252): "Dá-lhe, dá nesse patife, a sombra negra dos Cavaleiros (...). Vamos, dá-lhe para baixo, persegue-o, atormenta-o, chateia-o, detestao".

Pancadas e agressões são também a arma da concorrência entre candidatos ao voto do povo. São, portanto, um exercício repetido entre o Paflagônio, instalado no poder, e o Salsicheiro, o futuro procurador de Demos (v. 294-295). É esse o primeiro requisito de uma política com sucesso: dar e levar, sempre em nome do povo (v. 730731), e naturalmente também em nome dos interesses particulares de cada um. Transformando a arena política no recinto de luta, o candidato besunta-se (v. 490-495) para deslizar entre as calúnias adversárias, com um produto - o alho - que faz dele uma espécie de galo de briga. Esta é uma imagem oportuna para um novato que ingressa na carreira política.

Ao vigor das pancadas associa-se o impacto do discurso. E, desta capacidade, o político tem de possuir todos os segredos. Mais do que as palavras articuladas, a retórica acredita na eficácia dos gritos. Estes são impulsos viscerais que corporizam o talento, e outras tantas "pancadas" verbais sobre os concorrentes. Constituem uma espécie de manifestação da phýsis política. Para o sugerir, Aristófanes insiste nas onomatopeias, sendo krázo a mais sugestiva: kékragas (v. 274), kekráxomai sou (v. 285), katakekráxomai te krázon (v. 287), krágon kekráxetai (v. 487). Talvez até as guturais em que a onomatopeia insiste reproduzam a voz rouca e tonitruante de Cléon, aquele estrépito a que se associavam a exuberância do gesto, a prolixidade do discurso, a violência do argumento. Esta é a versão cômica daquilo que, em termos mais sóbrios, Tucídides mencionou como a imagem retórica de Cléon (3. 36. 6): "Além de ser, noutros aspectos, o mais violento dos cidadãos, era também de longe o mais capaz de persuadir a democracia da altura". A que Aristóteles acrescenta (Ath. Pol. 28. 3): "Era como fogo para gritar e insultar sobre a plataforma, pronunciava um discurso como um espetáculo, enquanto os outros o faziam em boa ordem”. Um ator expressivo não deixaria de valorizar, em cena, este traço caracterizador de Cléon.

Dos gritos progride-se para a palavra, o discurso estruturado, a rhêsis, como aquela versão que se usa para impressionar as instâncias do poder, o Conselho por exemplo. Sem ainda reproduzir propriamente um agón político, Cavaleiros regista todas 


\section{nuntius antiquus}

as nuances do efeito; de acordo com o padrão recente de orador, pouco culto, de origem humilde, mas aguerrido, o tom pode soar a voz de patife (v. 218), de desavergonhado (v. 638): para seduzir as massas, o demagogo conhece também "as palavrinhas delicodoces lá da sua especialidade" (v. 216). A prova de fogo desta habilidade, em Cavaleiros, tem por cenário a Boulé, onde se disputam discursos e propostas, culinários e políticos a uma só vez. Como perfeitos mágeiroi, os dois antagonistas manobram o discurso; e, perante eles, o auditório roda a cabeça, para um lado e para o outro, guloso das notícias felizes e dos petiscos que lhe prometem: peixe barato, carne com fartura para todos, e uma trégua duradoira com Esparta (v. 642-669).

Mais sofisticado é o estilo oracular, uma espécie de alternativa simbólica ao discurso político, de recursos múltiplos e de eficácia comprovada. São essas qualidades que justificam a abundância com que os oráculos são usados em Cavaleiros. Pareceu até provável que o próprio Cléon tivesse recorrido a esse artifício perante a assembleia, para fundamentar os seus pontos de vista. Servem para conquistar alianças políticas; é a eles que recorrem os dois escravos para garantir a colaboração do Salsicheiro e para anunciar, em tom de predestinação, o seu momento de glória (v. 197-201): "Quando a águia dos coiros, de garras curvas, arrebatar no bico a serpente tacanha, chupadora de sangue, é o fim do escabeche dos Paflagônios. Aos toucinheiros os céus destinam grande glória, a não ser que prefiram continuar a vender chouriços". Mas sobretudo são a materialização sonora das promessas com que os demagogos aliciam o povo. $\mathrm{O}$ próprio estilo ambíguo que os caracteriza produz o efeito pretendido: dá o tom da transcendência, fazendo dos seus autores uma espécie de inspirados; sublinha o seu caráter enigmático, útil para camuflar a falsidade das promessas. O exagero, simbólico ou virtual, é também seu atributo: prometer ao povo de Atenas que será juiz na Arcádia com cinco óbolos de salário por dia (v. 797-799) é uma alquimia, que faz de uma realidade modesta uma fantasia fulgurante (já não se trata apenas de controlar as ilhas e as zonas costeiras, mas de interferir com um espaço terrestre e fechado como a Arcádia, e assim confrontar a superioridade que Esparta detinha nesse outro terreno). À medida que as dificuldades aumentam ou que a concorrência política se torna mais feroz, os oráculos sobem de generosidade e cruzam-se como arma de arremesso. É assim que, na hora decisiva para o Salsicheiro, o despique é também de oráculos (v. 960 ss.). Nesse momento as palavras ganham vida, como conteúdo de um baú pesado, difícil de arrastar para a ribalta pública, de onde saem as promessas mais imprevisíveis (v. 997 ss.). 
Retirados do baú e recitados um a um, os oráculos ganham forma e funcionam como um certo tipo - utópico - de presentes para o povo. De que falam essas profecias? Do que está na ordem do dia, naturalmente. Há os que promovem o seu autor: assim os do Paflagônio falam "De Atenas, de Pilos, de ti, de mim, de tudo em geral" (v. 1005-1006). Mais persuasivos são aqueles que satisfazem as expectativas da populaça, os do Salsicheiro (v. 1007-1010): "De Atenas, de sopa de lentilhas, dos Lacedemônios, de cavalas fresquinhas, dos que roubam à farinha no mercado, de ti, de mim". Cada um vai construindo, à sua medida, um trajecto até ao limite da fantasia, nada menos do que "hás-de ser águia entre as nuvens" (v. 1013).

À demagogia não faltam recursos, de que Aristófanes alarga o catálogo. Além dos oráculos, há as promessas de amor. "Porque te quero muito, meu Povo, porque estou doido por ti” (v. 732-735, v. 779-780, v. 1163, v. 1341 ss.) são declarações que Demos irá reconhecer, quando no final da peça recupera a lucidez, que são um argumento poderoso para lhe bloquear a razão e fomentar nele um narcisismo perigoso. A persistência com que Aristófanes insiste em composições com o primeiro elemento philo-, ou o seu antônimo miso- (filodemos, misodemos, filopolis, misopolis), em contextos onde está em causa a figura de Cléon, foi tomado por alguns como paródia do seu estilo oratório. Nas entrelinhas, Aristófanes estaria a transmitir-nos o discurso exuberante do demagogo, com os protestos de dedicação ao povo e à cidade, através de compostos vistosos. Em graduação crescente, as promessas e os protestos de amor vão dando lugar à prenda concreta, na comédia reproduzida em bens de consumo. $\mathrm{O}$ Paflagônio depõe aos pés do povo vantagens políticas concretas - numa alusão às intervenções do Cléon real na política ateniense; o Salsicheiro serve-se de presentes à altura da sua personalidade.

Não é preciso muito para cativar o Povo; basta garantir-lhe o que lhe dá conforto e lhe regala o estômago. Em vez do esforço, com que construiu as vitórias do passado, dê-se ao povo uma almofada (v. 781-785); ofereça-se-lhe um par de sapatos, que até hoje o fabricante de peles não se dignou oferecer-lhe (v. 868-876); aqueça-se-lhe os dias com uma túnica e uma camisa (v. 881-886, v. 890-891); dê-se-lhe o conforto de um banco e de uma mesa (v. 1164-1165), imagem de descanso e de fartura, uma espécie de utopia urbana. Mas mais do que a qualquer outra oferta, é a comida o que melhor garante o entusiasmo de demos, ou não fosse a política "a arte de empanturrar". Um cesto cheio de petiscos centraliza a imagem da convivência política, entre demagogos e 


\section{nuntius antiquus}

destes com o povo (v. 716-718). Ao anunciar o movimento de cena, o Salsicheiro pode resumir: "Depois, como fazem as amas, roubas-lhe na comida. Esmagas-lhe a papa, metes-lhe um pedacinho na boca, e tratas tu de engolir três vezes mais do que ele". Este é o mote que anuncia a prova decisiva. Sob forma de um certame desportivo, os dois se prestam a participar numa corrida pela "boa vontade" do seu senhor (v. 1151 ss.). Se os petiscos se inspiram numa ementa vulgar - pão e doces, uma sopa de legumes, uma posta de peixe ou de carne, v. 1166-1179 -, o sentido da competição sublinha-se pelo tamanho e qualidade das ofertas. "O dedo de Atena", a deusa da cidade, garante-lhe o patrocínio. Foi ela, no dizer dos demagogos, quem moldou as empadas, quem ralou o purê, quem serviu a sopa, quem ofereceu o peixe e a carne, quem misturou o vinho. Regressando ao tópico inicial - o roubo do pãozinho da Lacônia -, é desta vez o Salsicheiro a consumar a vitória com a mesma batota: das mãos do rival arrebata um pedaço de lebre para presentear o povo (v. 1199-1201). Uma última comprovação abrir o cesto de cada um e verificar o que contém - garante vantagem ao Salsicheiro, ele que generosamente esvaziou a sua em favor do povo (v. 1211 ss.). É em volta da cesta dos petiscos que se decide o último agón. Ou seja, é a generosidade dos seus aduladores o que determina o voto popular.

No entanto o novo demagogo surpreende tudo e todos com a sua cesta vazia. É esta a razão por que o Salsicheiro é saudado como um salvador, apesar de se ter mostrado até agora o demagogo em superlativo. A mensagem da peça reside, em boa parte, nesta surpresa dramática. Talvez, segundo Sommerstein, “o povo ateniense consiga os leaders políticos que merece"; ou, pelo contrário, que para uma Atenas envelhecida há ainda uma esperança: a da vinda messeânica de um verdadeiro leader, que a leve de volta aos seus dias de esplendor. Fica em aberto a grande interrogação da peça: que relação, entre o povo e os seus leaders, pode garantir o sucesso a uma Atenas democrática?

Convencido, Demos distingue-o com as insígnias devidas ao seu homem de confiança, a coroa do vencedor (v. 1227 ss., v. 1250-1253), mais tarde, o trajo verde, festivo (v. 1406), e as honras do Pritaneu. Dentro desta nova ordem que acaba de se instaurar, a magia substitui o truque político. O próprio Demos experimenta um processo de revitalização. É também no âmbito culinário - e, ao mesmo tempo, das artes mágicas - que ele se remoça, com uma cozedura leve, para aparecer, como uma epifania, aos olhos do público (v. 1315 ss.). Pela competência do Salsicheiro, a 
metamorfose que se operou é a recuperação do passado, o regresso à prosperidade do antigamente. Em toda a plenitude, Demos atravessa os Propileus, a moldura ideal de um retrato do passado, com um trajo antigo, a recordar os Aristides "justos" ou os Milcíades "vencedores de Maratona" e os dias de glória. Essa é a imagem "da velha Atenas, admirável e tão celebrada, morada do glorioso Povo" (v. 1325-1328). Com o broche da cigarra nos cabelos (como nos velhos tempos das guerras pérsicas), no esplendor do seu trajo antigo (v. 1331-2), perfumado e oleado, o Povo recuperou também a sensatez de outrora: a imunidade aos elogios gratuitos, à persuasão das prendas, à sedução da retórica. Como primeiro gesto da nova ordem, o Povo desposa a Trégua por trinta anos, a encarnação da beleza, uma promessa de paz e felicidade que se consuma fora da cidade, no regresso aos campos. Com esta boda simbólica, Atenas redimia-se dos excessos que a trouxeram ao envelhecimento e revigorava-se por um milagre só possível no cenário utópico da comédia: o retorno à saudosa glória passada."

\section{Referências}

ARNOTT, P. Greek scenic conventions in the fifth century b.C. Oxford: University Press, 1962.

DEARDEN, B. W. The stage of Aristophanes. London: Athlon Press, 1976.

DESFRAY, S. Oracles et animaux dans les "Cavaliers" d'Aristophane. Antiquité Classique. Bruxelles, vol. LXVII, p. 35-36, 1999.

DOREY, T. A.. Aristophanes and Cleon. Greece \& Rome. Cambridge, $2^{\text {nd. }}$ ser., vol. III, p. 132-139, 1956.

K. J. DOVER. Portrait-masks in Aristophanes'. Komoidotragemata. Amsterdam, p. 16$28,1967$.

Press, 1972.

Aristophanic Comedy. Berkeley and Los Angeles: University of California

EDMUNDS, L. The aristophanic Cleon's "disturbance" of Athens. American Journal of Philology. Baltimore, vol. CVIII, p. 233-263, 1987.

EHRENBERG, V. The people of Aristophanes. Oxford: University Press, 1951. 
HARRIOTT, R. Aristophanes. Poet and dramatist. London: The Johns Hopkins University Press, 1986.

HEATH, M. Political comedy in Aristophanes. Gottingen: Vandenhoeck and Ruprecht, 1970.

LÓPEZ EIRE, A. La lengua de la comedia aristofánica. Emerita. Madrid, vol. LIV, p. 237-274, 1986.

MACDOWELL, D. M. Aristophanes and Athens. Oxford: University Press, 1995.

MCLEISH, K. The theatre of Aristophanes. Essex: Taplinger, 1980.

LEVER, K. The art of Greek comedy. London: Methuen, 1956.

MASTROMARCO, G. Il commediografo e il demagogo. In: A. H. Sommerstein, S. Halliwell, J. Henderson, B. Zimmermann, Tragedy, comedy and the polis. Bari: Levante Editori, p. 341-357.

. Introduzione a Aristofane. Bari: Laterza, 1994.

MCGLEW, J. Everybody wants to make a speech: Cleon and Aristophanes on politics and fantasy. Arethusa. Baltimore,vol. XXIX, p. 339-361, 1996.

MOULTON, C. Aristophanic poetry. Hypomnemata. Gottingen: Vandenhoeck \& Ruprecht, 1981. Heft LXVIII.

RECKFORD, K. J. Aristophanes' Old-and-New Comedy I: six essays in perspective. Chapel Hill: The University of North Carolina Press, 1987.

RUSSO, C. F. Aristophanes. An author for the stage. London: Routledge, 1994.

SEGAL, E. (org.). Oxford readings in Aristophanes. Oxford: University Press, 1996.

SILK, M. S. Aristophanes and the definition of comedy. Oxford: University Press, 2000.

SILVA. M. F. Crítica do teatro na Comédia Antiga. Lisboa: JNICT/ Gulbenkian, 1997. 
SOMMERSTEIN, A. H. Notes on Aristophanes' "Knights". Classical Quaterly. Cambridge, vol. XXX, p. 46-56, 1980.

SUTTON, D. F. Self and society in Aristophanes. Washington: Rowman \& Littlefield, 1980 .

THIERCY, P. Aristophane: fiction et dramaturgie. Paris: Les Belles Lettres, 1986.

France, 1999.

Aristophane et l'Ancienne Comédie. Paris: Presses Universitaires de

WELSH, D. The ending of Aristophanes "Knights". Hermes. Stuttgart, vol. CXVIII, p. 421-429, 1990.

Further observations on the ending of the "Knights". Hermes. Stuttgart, vol. CXX, p. 377-380, 1992.

WHITMAN, B. H. Aristophanes and the comic hero. Cambridge, Mass.: Harvard University Press, 1964. 